\title{
DE LOS BIENES Y DE SU DOMINIO, POSESIÓN, USO Y GOCE
}

Jaime Alcalde Silva

Profesor asistente Derecho Privado

Pontificia Universidad Católica de Chile

CRÓNICA DE UNA SOLUCIÓN ANUNCIADA: EL APARENTE EPÍLOGO DEL CASO DE LOS SUBARRENDATARIOS DEL ASÍ LLAMADO "MALl DEL MUEble" QUE NO FUERON NOTIFICADOS DE LA DEMANDA SEGÚN LO DISPUESTO EN EL ART. 11 DE LA LEY N ${ }^{\circ}$ 18.101, COMENTAdo en REVISTA CHILENA de Derecho Privado. No 25. Santiago. 2015, Pp. 231-256. $11^{\circ}$ JuzGado Civil de Santiago, sentencia de 18 DE AGOSTO DE 2016, ROL N E-42-2014*

\section{LA CUESTIÓN DISCUTIDA}

En el comentario publicado en el $\mathrm{N}^{\circ} 25$ de esta revista (pp. 231-256) se abordó el caso del lanzamiento de los subarrendatarios del inmueble situado en la manzana comprendida entre las calles San Diego, Placer, Centenario y Arturo Prat de la comuna de Santiago y conocido popularmente como "Mall del mueble" . Dicha medida fue decretada por resolución del $11^{\circ}$ Juzgado Civil de Santiago de fecha 14 de octubre de 2015, en cumplimiento de la sentencia de 18 de junio de 2013 pronunciada

\footnotetext{
* Este comentario hace parte del proyecto FONDECYT de iniciación $\mathrm{N}^{\circ} 11160615$, del cual el autor es investigador responsable.

${ }^{1}$ Alcalde (2015).
}

por Claudio Illanes Ríos actuando como árbitro arbitrador designado por el Centro de Arbitraje y Mediación de la Cámara de Comercio de Santiago en los autos rol CAM No $1572-2012$.

En esa ocasión se hizo presente que los dos juicios seguidos ante el mismo árbitro arbitrador habían sido mal tramitados en lo que atañía a la protección de los subarrendatarios, que eran en realidad los usuarios finales del inmueble arrendado por D\&S (después sucedida por Walmart Chile S.A.) a la Inmobiliaria Carmona Hermanos S.A. La razón es que la ley $\mathrm{N}^{\mathrm{O}}$ 18.101 crea un orden público de protección a favor de los arrendatarios y subarrendatarios, declarando que los derechos en ella reconocidos tienen el carácter de irrenunciables (art. 19) ${ }^{2}$.

En este sentido, el hecho de que el contrato de arrendamiento original estipulase que las controversias debían ser sometidas al conocimiento de un árbitro arbitrador, quien había de fallar obedeciendo a lo que su prudencia

${ }^{2}$ Con todo, la SCA Concepción 24 de marzo de 2015 (CL/JUR/1660/2015) señaló que el art. 19 de la ley $\mathrm{N}^{\circ} 18.101$ solo se refiere a los derechos sustantivos y no a los procesales adjetivos, de manera que la sola sustitución de una jurisdicción por otra no puede ser considerada renuncia de derechos. 
y equidad le dictaren y sin estar obligado a guardar en sus procedimientos y fallo otras reglas que aquellas que las partes hayan expresado en el acto de constitución del compromiso (art. 223 III del COT), no eliminaba la necesidad de observar dicho orden público de protección respecto de la parte más débil. En sede arbitral podían alterarse las normas de sustanciación en cuanto al procedimiento aplicable (reemplazando aquel previsto en el art. $8^{\circ}$ de la ley $\mathrm{N}^{\mathrm{O}} 18.101$ por el que conviniesen las partes en el acto de constitución del compromiso), y aun los criterios conforme a los cuales el juez debía dictar sentencia (resolviendo ahora conforme indiquen la equidad y prudencia del árbitro), pero de ahí no podía seguirse una desprotección para los arrendatarios ni los subarrendatarios, porque eso suponía un abuso objetivo de la norma de cobertura aplicable y, por consiguiente, un fraude de ley ${ }^{3}$. Así, pues, de aceptarse la corrección del fallo arbitral y su posterior cumplimiento forzado en sede civil, se estaría admitiendo que a través de una cláusula compromisoria se pueda vulnerar un orden público de protección establecido a favor de la parte más débil de una relación contractual ${ }^{4}$.

Concretamente, en el caso comentado se había omitido por parte del arrendador demandante el trámite de denuncia del litigio previsto en el art. 11 de la ley $\mathrm{N}^{\mathrm{O}} 18.101$, que dispone que la sentencia dictada contra el

${ }^{3}$ Carrasco (2016), p. 332.

${ }^{4}$ Algo parecido ocurre en materia de consumo, donde existe una vasta bibliografía respecto del arbitraje como medio de solución de controversias. Véase, por ejemplo, Bujosa (2013), y el art. $55 \mathrm{~N}^{\circ} 3$ de la LPDC. arrendatario solo es oponible al subarrendatario si ya se le ha notificado también la demanda, permitiendo que pueda apersonarse en juicio y formular los descargos que estime convenientes, incluso pagando la renta que se demanda a su subarrendador cuando esto corresponde (art. 12 de la ley $\mathrm{N}^{0}$ 18.101). No se trata, por cierto, de una norma decisoria del asunto, pues no permite resolver el conflicto entre arrendador y arrendatario dando la razón a uno u otro, sino de ordenación del litigio, con el fin de que la sentencia que ahí se dicte pueda hacerse valer contra el subarrendatario ${ }^{5}$. Es, con todo, un medio de protección del subarrendatario, que de esa manera se entera de que existe un juicio contra su subarrendador.

En el caso narrado en el comentario antes referido se habían iniciado dos juicios arbitrales. En el primero, D\&S demandó la terminación del contrato de arrendamiento suscrito con Inmobiliaria Carmona Hermanos S.A. por el vencimiento del plazo convenido y la consiguiente restitución del inmueble. Este juicio concluyó por sentencia de 27 de abril de 2006 y en ella se acogió en todas sus partes la demanda. Los recursos de casación en la forma y queja deducidos por la demandada fueron desestimados por la Corte de Apelaciones de Santiago. Dado que el inmueble siguió siendo ocupado por los locatarios que trabajaban en el lugar, Walmart Chile S.A. (sucesora de D\&S desde 2010) inició un segundo procedimiento arbitral y solicitó el lanzamiento de Inmobiliaria Carmona Hermanos S.A. El 18 de junio de 2013,

${ }^{5}$ SCS 2 de noviembre de 2015 (CL/JUR/ 6619/2015). 
el árbitro dictó sentencia acogiendo la demanda de lanzamiento y declarando que procedía practicar dicha diligencia respecto de la propiedad de San Diego 3220, comuna de Santiago, recurriendo a las instancias judiciales y administrativas que permitiesen hacer efectiva esa decisión.

Fue esta última sentencia la que se solicitó fuese cumplida mediante exhorto ante el $11^{\circ} \mathrm{Juzgado}$ Civil de Santiago, quien acabó decretando el lanzamiento con auxilio de la fuerza pública por resolución de 14 de octubre de 2015. Esta resolución fue cumplida durante buena parte de la jornada del 21 de octubre de ese año, con un amplio despliegue policial y de prensa, procediendo Carabineros a cerrar y sellar las cortinas metálicas del recinto para impedir el acceso de los locatarios expulsados. La mayoría de ellos abandonó de forma definitiva el lugar, reinstalando sus comercios en otros lugares más o menos cercanos (por ejemplo, en la no tan lejana avenida Manuel Antonio Matta de la misma comuna de Santiago, conocida por ser un sector de tiendas dedicadas a la fabricación y venta de muebles). Por su parte, sesenta locatarios suscribieron una transacción con Walmart S.A. mediante la cual renunciaban a cualquier derecho relacionado con el subarriendo vigente que les permitía utilizar el inmueble en discusión a cambio de una suma de dinero.

El verdadero encuadre del problema demostraba que el lanzamiento del art. 595 del $C P C$, que el art. 13 de la ley $\mathrm{N}^{\circ} 18.101$ hace aplicable para los procedimientos derivados del arrendamiento de predios urbanos, no era factible en una situación como la planteada entre Walmart Chile S.A. e Inmobiliaria Carmona Hermanos S.A., pues la sentencia arbitral (aquella de 2006) que se hizo cumplir de esta forma había perdido su ejecutoriedad por haber prescrito la acción de cumplimiento que de ella emanaba (arts. 2515 del $C$ Cy 234 del CPC), fuera de la imposibilidad legal de acudir a arbitraje para solicitar un procedimiento de apremio (art. 635 del $C P C$ ), sin cumplir en ningún momento con las medidas de resguardo de terceros (art. 11 de la ley $\mathrm{N}^{\circ}$ 18.101).

De esta manera, el segundo juicio iniciado por Walmart Chile S.A. buscaba sanear ese título ya prescrito, aunque renovando la condena sobre la base de la primera sentencia arbitral que se invocaba para el lanzamiento. La contradicción en la causa de pedir era así evidente, y el árbitro Claudio Illanes Ríos debió de haber rechazado la pretensión de dicha compañía por ser contradictoria con su propia conducta observada respecto de la relación sustantiva existente entre las partes, dado que por más de seis años no hizo nada para dar cumplimiento al primer fallo ${ }^{6}$.

Pues bien, finalmente se hizo justicia en el caso que se viene recordando, pero no de la forma que fue anunciada en el comentario ya citado. Por sentencia interlocutoria de 9 de junio de 2016, el $11^{\circ}$ Juzgado Civil de Santiago proveyó una presentación de 30 de mayo hecha por el abogado de treinta y siete locatarios donde se solicitaba el apercibimiento de la Dirección de

${ }^{6}$ CARrasco (2016), pp. 517-537, dedica una extensa explicación a esta figura, que se conoce como retraso desleal y se considera como uno de los casos de abuso relacional. 
Obras de la Ilustre Municipalidad de Santiago y de Walmart Chile S.A. respecto de las obras de demolición del galpón metálico existente en el bien raíz situado en San Diego 3220. En dicha resolución, el tribunal comienza con una recapitulación de la situación producida en autos durante la tramitación del exhorto y enseguida constata el nuevo estado de cosas del que corresponde hacerse cargo.

El $11^{\circ}$ Juzgado Civil de Santiago empieza recordando que, desde el inicio de la tramitación del exhorto, se ha sostenido que el cumplimiento del fallo arbitral se dirige de manera exclusiva contra Inmobiliaria Carmona Hermanos S.A., pues ella fue la única demandada en los dos juicios seguidos ante el árbitro designado por el Centro de Arbitraje y Mediación de la Cámara de Comercio de Santiago. Siendo esto así, solo por razones de seguridad para permitir el retiro de la estructura metálica existente al interior del bien arrendado se dispuso que los ocupantes fueran desalojados temporalmente. De ningún modo eso supuso una decisión definitiva, puesto que ellos no eran parte del juicio.

Sin embargo, después de dicho desalojo no hubo ninguna gestión positiva de parte de Walmart Chile S.A. para avanzar en el retiro de la estructura metálica que se hallaba erigida al interior del predio de calle San Diego 3220. En tal sentido, no resultaba posible escudarse en el retraso de la municipalidad cuando ya habían transcurrido más de tres meses desde que se presentó la documentación para que se autorizase la demolición, sin que entretanto se hubiese efectuado trámite ni presen- tación alguna destinada a obtener una respuesta satisfactoria de la Ilustre Municipalidad de Santiago. Tampoco Inmobiliaria Carmona Hermanos S.A. realizó ninguna presentación destinada a que el inmueble le fuese restituido. De ahí, entonces, que cabía asumir que las partes litigantes habían perdido interés en la prosecución del proceso.

De tal manera, el tribunal reconoce que le era imposible seguir con el cumplimiento de la sentencia arbitral en lo que atañía a la estructura metálica, por lo que correspondía autorizar el reingreso de las personas que, teniendo la calidad de terceros al juicio, ocupaban el inmueble arrendado. Para ese efecto, el reingreso había de ser vigilado, resguardado y asegurado por Carabineros.

A través de sus nuevos abogados, Walmart Chile S.A. repuso con apelación subsidiaria la resolución de 9 de junio de 2016 al día siguiente de su dictación. Después de pedir la remisión del exhorto que había sido devuelto al Centro de Arbitraje y Mediación de la Cámara de Comercio de Santiago y de dictar algunos decretos de mero trámite, el $11^{\circ}$ Juzgado Civil de Santiago reiteró lo previamente resuelto, ordenando que Carabineros diese cumplimiento a lo ya decretado. En esta resolución de 26 de julio de 2016 se dijo una vez más que la arrendadora no había instado por la tramitación de la causa y se precisó que se permitiría el reingreso al inmueble de todos aquellos locatarios que habían intentado ser parte del exhorto durante su tramitación. Walmart Chile S.A. volvió a reponer con apelación subsidiaria esta segunda resolución, reiterando que ella había 
realizado gestiones para llevar adelante el cumplimiento del fallo arbitral. Fue así como, por sentencia de 29 de julio de 2016, se dejó sin efecto lo precedentemente resuelto, disponiendo el tribunal que se practicase el desarme íntegro del galpón que existía en el inmueble de calle San Diego 3220 conforme a lo dispuesto en la resolución de 26 de diciembre de 2014, complementada después por aquella de 14 de octubre de 2015.

Tras algunas presentaciones de las partes, el 18 de agosto de 2016 se dictó una resolución que ordenó poner fin a la tramitación del exhorto y permitir definitivamente el ingreso de treinta y siete locatarios al inmueble de autos, puesto que Inmobiliaria Carmona Hermanos S.A. ya había sido por completo desalojada y el galpón desmontado en su totalidad. Dicha resolución calificó también la destrucción de una losa de concreto y la instalación de un cerco al interior del inmueble para delimitar la zona que podía ocupar los locatarios como

"un acto de fuerza que no se ajusta a la conducta que debe observar una empresa en un Estado de Derecho" (considerando $4^{\circ}$ ),

recordando a la parte demandante que no puede impedir la reubicación de dichas personas sin que eso suponga un incumplimiento de lo decretado por el tribunal (considerando $5^{\circ}$ ).

Por presentación de 24 de agosto de 2016, Walmart Chile S.A. repuso con apelación subsidiaria esta última resolución. El argumento es que los locatarios que reingresen al inmueble deben ser aquellos desalojados en 2015 y que a la fecha tengan un contrato de subarriendo que les permita permanecer ahí. A través de una resolución del día siguiente, el $11^{\circ}$ Juzgado Civil de Santiago rechazó la reposición y concedió la apelación?

Con posterioridad se han presentado otros escritos en el exhorto, sobre todo relacionados con el ingreso de otros subarrendatarios o de personas relacionadas con ellos, pero estos últimos no resultan relevantes para la cuestión que aquí interesa.

\section{Comentario}

La decisión del $11^{\circ}$ Juzgado Civil de Santiago es importante porque demuestra que los subarrendatarios no son parte del procedimiento de cumplimiento forzoso del fallo arbitral de lanzamiento del predio arrendado por Walmart Chile S.A. a Inmobiliaria Carrasco Hermanos S.A. Su exclusión es originaria, porque nunca se los emplazó como dispone el art. 11 de la ley $\mathrm{N}^{\mathrm{O}}$ 18.010. Esto significa que ni la primera sentencia arbitral de terminación del contrato de arrendamiento y restitución del inmueble arrendado ni la segunda de lanzamiento eran oponibles a los más de doscientos subarrendatarios del inmueble de calle San Diego 3220 y, por consiguiente, respecto de ellos no existe acción de cosa juzgada que permita conseguir la restitución material de dicho inmueble (art. $175 \mathrm{del} C P C)^{8}$.

${ }^{7}$ La apelación no ha sido conocida a esta fecha (2 de noviembre de 2016) por la Corte de Apelaciones de Santiago.

${ }^{8}$ Alcalde (2015), pp. 241-242. 
Con todo, la sentencia de 18 de agosto de 2016 aboca hacia tres cuestiones interesantes.

La primera es la restricción de los efectos que en ella se efectúa respecto de la sentencia arbitral de 18 de junio de 2013 que se cumplía mediante exhorto ante el $11^{\circ}$ Juzgado Civil de Santiago. De acuerdo con el art. 70 III del $C P C$, el tribunal exhortado

“ordenará su cumplimiento en la forma que ella indique, y no podrá decretar otras gestiones que las necesarias a fin de darle curso [...]".

Esto significa que el tribunal exhortado opera como mero ejecutor de la decisión de aquel tribunal que le remite la comunicación, siendo este el que debe resolver lo conveniente si se promueve alguna incidencia (art. 70 III del CPC).

La sentencia arbitral de 18 de junio de 2013 disponía el lanzamiento de Inmobiliaria Carmona Hermanos S.A. del inmueble que seguía ocupando, de suerte que el tribunal exhortado debía realizar todo lo posible para conseguir que dicho bien fuese restituido al arrendador. Claro está, esa restitución solo podía lograrse en la medida de lo posible según las circunstancias concretas del caso, pues una sentencia solo admite cumplimiento contra quien se haya declarado un derecho en juicio (art. 175 del CPC). De esa manera, si el inmueble estaba ocupado por terceros en calidad de subarrendatarios y contra ellos no se notificó inicialmente la demanda, solo la sentencia dictada en el juicio de arrendamiento es inoponible a ellos y no les afecta el procedimiento de apremio (art. 11 de la ley $N^{\circ} 18.101$ y 234 del $C P C$ ). Simplemente hay ahí un caso de imposibilidad jurídica que impide lograr el cumplimiento de la condena arbitral. Por eso, resulta razonable que el $11^{\circ}$ Juzgado Civil de Santiago limitase los efectos del fallo arbitral que ordenaba el lanzamiento al retiro del galpón que existía en el inmueble, pues era lo único que podía llevarse a cabo sin vulnerar derechos de terceros ajenos al juicio. Más todavía, el desalojo temporal fue especialmente previsto para evitar que en la faena de retiro se les ocasionase algún perjuicio.

La segunda cuestión de interés se refiere a la situación en que queda el arrendador. A estas alturas parece claro que Walmart Chile S.A. ya tiene asumido que erró el camino a seguir y que la acción fue mal planteada desde el primero juicio, sin que pueda obtenerse más de lo que se ha conseguido hasta el momento en sede judicial o merced a las transacciones con algunos locatarios. La voluntad del tribunal de devolver el exhorto al árbitro es una muestra de que entiende agotadas las actuaciones que se le solicitaron (art. 71 del $C P C$ ). Sin embargo, el problema para el arrendador persiste, pues en el inmueble de calle San Diego 3220 quedan los locatarios cuyo reingreso fue permitido merced a la resolución de 18 de agosto de 2016 que motiva este comentario.

Esto lleva a preguntarse de nuevo, ¿cuáles son los cursos idóneos a seguir para que el arrendador pueda recuperar la tenencia material del inmueble? En el comentario anterior se hizo mención a las acciones que resultaban procedentes contra el arrendatario después de descartada la posi- 
bilidad de demandar el lanzamiento ${ }^{9}$. Esta vez la atención gira en torno a las acciones que cabe intentar contra los locatarios, pues es ya un hecho indubitado que el contrato de arrendamiento está terminado desde que la primera sentencia arbitral quedó firme y que Inmobiliaria Carrasco Hermanos S.A. no ocupa en realidad el inmueble. La acción idónea para conseguir la restitución del inmueble parece ser aquella del art. 915 del $C C$, por las mismas razones dadas en el comentario que ahora se epiloga ${ }^{10}$. Ni la acción de precario ni las relacionadas con el contrato de arrendamiento parecen oportunas en la especie.

La tercera cuestión que resulta relevante es la sanción a la pérdida de interés que aplica de oficio el $11^{\circ}$ Juzgado Civil de Santiago en la resolución de 9 de junio de 2016 y que todavía se intuye detrás del razonamiento de la posterior sentencia de 18 de agosto de 2016. Tal resolución se pronuncia sobre un escrito donde se pedía el apercibimiento del arrendador, y también de la Ilustre Municipalidad de Santiago, por no haber efectuado ninguna gestión destinada a seguir adelante con el desarme del galpón. El tribunal entiende que la inactividad de la parte demandante muestra la pérdida sobrevenida de su interés, de suerte que corresponde devolver el exhorto al tribunal arbitral $\mathrm{y}$ poner fin a su cumplimiento. Se trata de una situación de terminación anticipada de un juicio no reconoci-

${ }^{9}$ Alcalde (2016), pp. 244-254.

${ }^{10}$ Sobre esta acción se ha escrito bastante en los últimos años. Véase BARCia (2014); BARRIENTOS (2005a), (2005b), (2006), (2007) y (2016), I, pp. 1058-1062; PÉrez (2014); SELMAN (2011); TAPIA (2015). da por nuestra legislación procesal, generalmente ligada a la satisfacción extraprocesal del interés que existía detrás de la tutela que se reclamaba al tribunal (por ejemplo, arts. 22 y 413 de la Ley de Enjuiciamiento Civil española). El Código de Procedimiento Civil solo contempla la inactividad como forma de acabar de forma anticipada un juicio, siempre bajo los supuestos concretos del incidente de abandono del procedimiento ${ }^{11}$. En la sentencia de 18 de agosto, empero, la razón de la devolución del exhorto es más bien la satisfacción de la parte demandante, que solo podía lograrse mediante el retiro del galpón existente en el interior del predio. La restitución material del inmueble no quedaba dentro de la tutela que podía conceder el $11^{\circ}$ Juzgado Civil de Santiago, porque su tenencia estaba en manos de terceros que no fueron emplazados en juicio por el arrendador.

\section{Conclusiones}

Después de casi un año, uno de los casos con mayor impacto mediático de 2015

${ }^{11} \mathrm{El}$ art. $2503 \mathrm{~N}^{\circ} 2^{\circ}$ del $C C$ fue modificado por la ley $\mathrm{N}^{\mathrm{o}} 6.162$, pues su redacción original señalaba que el beneficio de la interrupción de la prescripción se perdía cuando el demandante había cesado en la prosecución de la demanda por más de tres años. Relacionando esa norma con el art. 152 del $C P C$, resultaba que en ese evento se producía la figura denominada "abandono de la instancia”, que desde la ley $\mathrm{N}^{\mathrm{O}} 18.705$ tomó el nombre de "abandono del procedimiento" con que hoy se la conoce. El legislador quiso, entonces, dejar en claro que la prescripción dejaba de estar interrumpida si de declaraba el abandono del procedimiento. A su vez, la ley $\mathrm{N}^{\mathrm{o}} 6162$ redujo el plazo de inactividad de tres años a uno. 
ha sufrido un importante vuelvo a favor de los locatarios desalojados en su día por la policía. Dada la inactividad de Walmart Chile S.A. para instar por el cumplimiento de la sentencia arbitral que la favorecía, el $11^{\circ}$ Juzgado Civil de Santiago autorizó el reingreso de ciertos subarrendatarios, quienes solo habían debido abandonar el lugar momentáneamente mientras duraban las faenas de retiro de la estructura metálica que soportaba el galpón existente en el predio arrendado. Tales obras ya concluyeron, de suerte que no existe impedimento para que sus antiguos ocupantes vuelvan al inmueble de calle San Diego 3220.

Las últimas sentencias del $11^{\circ} \mathrm{Juz}-$ gado Civil de Santiago demuestran que los subarrendatarios jamás fueron emplazados en los juicios seguidos entre Walmart Chile S.A. (originalmente 282 D\&S) e Inmobiliaria Carmona Hermanos S.A., por lo que les era inoponible lo obrado y resuelto en ellos. Siendo así, ellos nunca han sido parte del procedimiento de apremio tramitado por exhorto y no puede forzárseles a abandonar la porción del inmueble que ocupan por no existir título en su contra.

Queda pendiente la forma en que Walmart Chile S.A. solucionará de manera definitiva el problema, pues hasta ahora no ha conseguido la restitución del inmueble. Solo la presencia del arrendatario inicial ha desparecido, persistiendo la ocupación de los locatarios con subarrendamientos vigentes. La lección que se extrae de esto es que un pleito mal tramitado puede traer insospechadas consecuencias y extenderse en el tiempo por más de una década.

\section{BibliografíA CITADA}

Alcalde Silva, Jaime (2015). "Las diversas acciones de restitución a favor del propietario de un bien raíz. La improcedencia de solicitar el lanzamiento a través de un juicio arbitral cuando han prescrito las acciones emanadas de la sentencia que condenó a la restitución del inmueble arrendado. La denuncia del litigio como medida protectora de los subarrendatarios. La aplicación de los arts. 915 y 2195 II del $C C$ como supuestos diferenciados de restitución. Tribunal arbitral (árbitro arbitrador Claudio Illanes Ríos), sentencia de 18 de junio de 2013, rol CAM núm. 1572-2012, cumplida mediante exhorto ante el $11^{\circ}$ Juzgado Civil de Santiago, rol núm. E-422014". Revista Chilena de Derecho Privado. No 25. Santiago.

Barcia Lehmann, Rodrigo (2014). "Una concepción errada de mera tenencia y posesión, conforme a la teoría de la posesión inscrita, recurrente en algunos fallos de la Excelentísima Corte Suprema”. Revista Chilena de Derecho Privado. No 22. Santiago.

Barrientos Grandón, Javier (2005a). "Acción reivindicatoria. Contra quién se puedereivindicar. Actual poseedor. Mero tenedor. Poseedor a nombre ajeno. "Posesión material". Reivindicación de inmueble inscrito. Interpretación del artículo 915 CC. Acción de precario". Revista Chilena de Derecho Privado. N $^{\circ}$ 4. Santiago.

Barrientos Grandón, Javier (2005b). "Acción de restitución. Mero tenedor. Poseedor a nombre ajeno. "Injusto detentador". Retención indebida. Reivindicación de inmueble inscrito. Mero tenedor. Interpretación del 
artículo 915 CC. Revista Chilena de Derecho Privado No 5 . Santiago.

Barrientos Grandón, Javier (2006). “Acción reivindicatoria. Contra quién se puede reivindicar. Mero tenedor. Poseedor a nombre ajeno. 'Posesión material'. Reivindicación de inmueble inscrito. Interpretación del artículo 915 CC". Revista Chilena de Derecho Privado. $\mathrm{N}^{\circ}$ 7. Sntiago.

Barrientos Grandón, Javier (2007). "Acción reivindicatoria. Contra quién se puede reivindicar. Poseedora nombre ajeno. Mero tenedor. Retención indebida. Interpretación del artículo 915 CC". Revista Chilena de Derecho Privado. No 8. Santiago.

Barrientos Grandon, Javier (2016). El código civil. Su jurisprudencia e historia, Edición crítica, concordada, comentada y anotada. Santiago: Thomson Reuters.

Bujosa BADELl, Lorenzo (2013). "El arbitraje de consumo". Revista Jurídica de Castilla y León. No 29. León.

Carrasco Perera, Ángel (2016). Tratado del abuso de derecho y del fraude de ley. Cizur Menor: ThomsonReuters/Civitas.
Pérez PeÑa, María Francisca (2014). "La protección del dueño ante quien retiene indebidamente un bien. Análisis jurisprudencial del artículo 915 del Código de Bello". Revista de Derecho de la Universidad Católica del Norte. $\mathrm{N}^{\circ}$ 21. Vol. 1. Antofagasta.

Selman Nahum, Aarueo (2011). "Artículo 915 del Código Civil: una solución jurisprudencial a la limitación de las acciones tradicionales". Revista Ius et Praxis. $\mathrm{N}^{\mathrm{O}}$ 17. Vol. 1. Talca.

Tapia Rodríguez, Mauricio (2015). "Reivindicación contra el injusto detentador. El controvertido y enigmático artículo 915 del Código Civil", en Manuel BARRÍA PAREdes et al. (eds.). Estudios de Derecho privado. Homenaje al Profesor Ramón Domínguez Águila. Santiago: ThomsomReuters.

$$
\text { Jurisprudencia citada }
$$

SCA Concepción 24 de marzo de 2015 (CL/JUR/1660/2015).

SCS 2 de noviembre de 2015 (CL/ JUR/6619/2015). 